\section{The Vitamin $\mathbf{B}_{12}$-Producing Ability of Intestinal Bacteria Isolated from Tilapia and Channel Catfish}

\author{
Haruo Sugita, * Chihiro Miyajima,* \\ and Yoshiaki Deguchi* \\ (Received August 9, 1989)
}

Lovell and his co-worker ${ }^{1,2}$ reported that the apparent rate of intestinal bacterial synthesis of vitamin $\mathbf{B}_{12}$ in tilapia Tilapia nilotica fed a vitamin $\mathbf{B}_{12}$-deficient diet (at least $11.2 \mathrm{ng}$ per $\mathrm{g}$ of body weight per day) was eight times that found in channel catfish lctalurus punctatus fed the same diet (ca. $1.4 \mathrm{ng} / \mathrm{g} /$ day) although they did not compare the intestinal microflora of those fish species. There is little information on the vitamin $B_{12}$-producing ability of fish intestinal bacteria except for carp Cyprinus carpio.3) The present study was carried out to investigate the vitamin $B_{12}$-producing ability of intestinal microflora from tilapia and channel catfish.

Feces were removed from each of the four specimens of tilapia (18.9-45.8 $\mathrm{g}$ in body weight) and channel catfish (3.9-5.3 g) which had been fed a pelleted diet (Nippon Haigo Shiryo), and microbiological examination was performed according to the previous paper. ${ }^{4)}$ About three strains for each genus which showed the highest count through the seven agar media used, were selected from each specimen and incubated in GAM broth (Nissui) at $25^{\circ} \mathrm{C}$ for 5 days under aerobic or anaerobic conditions. The culture was then assayed microbiologically for vitamin $\mathbf{B}_{12}$ using Lactobacillus leichmannii IAM 12066 (=ATCC 7830), ${ }^{5}$ ) and the amount of vitamin $B_{12}$ produced or consumed was calculated from the difference between the inoculated and uninoculated broths.

Viable count (CFU/g) of each bacterial genus in the tlapia's intestine was: Aeromonas, $2.5 \times 10^{8}-3.0 \times 10^{7}$; Plesiomonas, $2.0 \times 10^{8}-7.7 \times 10^{7}$; Enterobacteriaceae, nd (not detected)-1.8 $\times 10^{7} ;$ Pseudomonas, $4.5 \times 10^{8}-$ $5.6 \times 10^{\circ} ;$ Moraxella, nd-2.8 $\times 10^{4} ;$ Bacillus, nd-1.0 $\times$ $10^{8}$; Bacteroides type A, $2.8 \times 10^{8}-1.2 \times 10^{8} ;$ Bacteroides type B, $7.6 \times 10^{5}-3.1 \times 10^{7}$; other Bacteroidaceae, $3.8 \times$ $10^{8}-1.5 \times 10^{8} ;$ Clostridium, $7.6 \times 10^{5}-2.7 \times 10^{7}$; and total viable counts, $2.9 \times 10^{8}-1.5 \times 10^{9}$. On the other hand, the intestinal microflora (CFU/g) of channel catfish was: Aeromonas, $8.6 \times 10^{3}-5.1 \times 10^{8} ;$ Enterobacteriaceae, nd-7.8 $\times 10^{2} ;$ Pseudomonas, nd-1.7 $\times 10^{8}$; Acinetobacter, nd-7.8 $\times 10^{3} ;$ Bacillus, nd-1.8 $\times 10^{5} ;$ Bacteroidaceae, nd-8.0 $\times 10^{2} ;$ Clostridium, nd-2.0 $\times 10^{3} ;$ and total viable counts, $2.2 \times 10^{5}-6.8 \times 10^{\mathrm{B}}$. This result, along with the previous report, ${ }^{4}$ indicates that obligate anaerobes, especially Bacteroides type A, occur predominantly in the tilapia's intestine but poorly in the channel catfish's intestine.

Fig. 1 shows the vitamin $B_{12}$-producing ability (ng/ $\mathrm{m} / /$ optical density at $630 \mathrm{~nm}$ ) of bacterial strains. Of
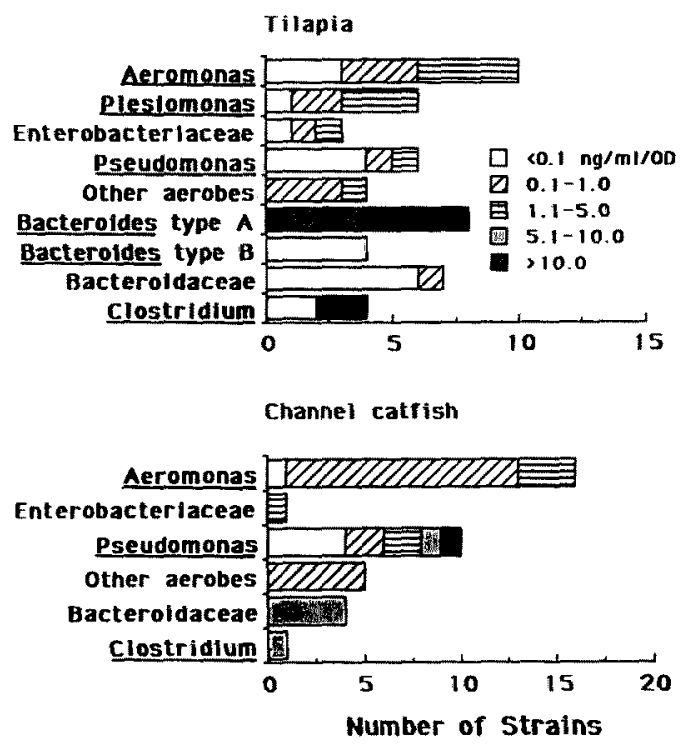

Fig. 1. The vitamin $B_{12}$-producing ability of intestinal bacteria from tilapia and channel catfish.

89 strains examined, 65 strains produced the vitamin $B_{12}$ whilst the other 24 strains consumed it. Especially 17 strains, consisting of $100 \%$ of Bacteroides type A, $60 \%$ of Clostridium, $36 \%$ of other Bacteroidaceae and $20 \%$ of Pseudomonas, synthesized the vitamin $\mathrm{B}_{12}$ efficiently ( $\left.>5.0 \mathrm{ng} / \mathrm{ml} / \mathrm{OD}_{630}\right)$. These results strongly suggest that the obligate anaerobes, including Bacteroides type $\mathrm{A}$, other Bacteroidaceae and Clostridium, are the imporant producer of this substance in the intestinal tract of freshwater fish. Therefore, the difference of the vitamin $B_{12}$-producing rate in the intestinal tract of tilapia and channel cattish may be attributed to the fact that the former harbours anaerobes abundantly whereas the later poorly. Additionally, the great difference of total viable counts between two fish species may be involved. Further studies along these lines are in progress.

We wish to express our gratitude to Mr. T. Ohkoshi, Saitama Prefectural Fisheries Experimental Station and Mr. M. Murai, Tokyo Metropolitan Fisheries Experimental Station for supplying the specimens.

\section{References}

1) T. Limsuwan and R. T, Lovell: $J$. Nutr., 111, 2125-2132 (1981).

2) R. T. Lovell and T. Limsuwan: Trans. Amer. Fish. Soc., 111, 485-490 (1982).

3) S. Teshima and K. Kashiwada: Nippon Suisan Gakkaishi, 33, 979-983 (1967).

4) H. Sugita, M. Tsunohara, M. Fukumoto, and Y. Deguchi: Nippon Suisan Gakkaishi, 53, 287290 (1987).

5) K. Sato: Vitamins (Japan), 57, 609-616 (1983).

* Department of Fisheries, Nihon University, Shimouma, Setagaya, Tokyo 154, Japan (柇田治男, 宫皇

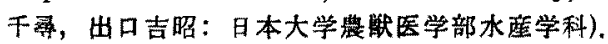

